\title{
Cultural legitimacy and regulatory transitions for climate change: A discursive framework
}

\author{
Thoko Kaime*
}

Because of its tremendous temporal and spatial scope, climate change poses profound regulatory issues. Significant transboundary effects and spatially differentiated effects make it highly desirable that international regulatory mechanisms are utilised in order to arrive at effective mitigation and adaptation solutions. Yet, the different spaces that states occupy in terms of causation and effect makes agreement on what must be regulated through international mechanisms and indeed how to regulate such subject matter. Consequently, this paper proposes that legitimacy needs to be considered one of the core concerns of international climate change regulation and governance. The aim of this paper is to clarify the role of the concept of legitimacy in international climate change regulation, and to set forth a specific discursive approach aimed at identifying legitimacy-enhancing design features for internationally regulating climate change.

\section{The problem of regulation in climate change: Spatial and temporal limitations}

International climate change regulation poses some fundamental legitimacy issues. This is principally because the spatial and temporal challenges thrown up by rising global temperature do not lend themselves to easy regulation for several reasons. ${ }^{1}$ Firstly, although atmospheric concentration of greenhouse gases around the globe is uniform, the impact of such concentration is not identical across the world. ${ }^{2}$ Consequently, different regions around the world will not experience the same temperature increase and the usual references to averages in reports mask fact that some places will suffer greater increases. Additionally, governments' public provision in services such as health, water, food and others are highly dependent on geographic location. Consequently, coping with climate change impacts will depend on the nations in which citizens find themselves. For example, the ability of the government of Malawi to provision these public services is not the same as that of the government of Malaysia. ${ }^{3}$ Again, location will drive the consequences of temperature increases across the globe. For example, temperature increases in places where water already scarce will lead to drought but not so much where water is already abundant. Similarly, the impact of increases in the ocean level will be greater in low lying islands where a small increase in ocean level will obliterate coastal communities, if not submerge entire islands. One might contrast this with communities in higher latitudes, for whom higher temperatures might translate to a longer growing season and therefore increased agricultural production. ${ }^{4}$ The point is that although all parts of the world can contribute to climate change, they will not suffer the consequences to the same degree and

\footnotetext{
* Thoko Kaime is a Lecturer in Laws at the School of Law; and Deputy Director of the Environmental Regulatory Research Group, University of Surrey, tkaime@surrey.ac.uk.

1 IPCC, Climate Change2001: Impacts, Adaptation \& Vulnerability Contribution of Working Group II to the Third Assessment Report of the Intergovernmental Panel on Climate. Change (Cambridge, UK: Cambridge University Press, 2001).

2 IPCC, Fourth Assessment Report, Working Group I, Summary for Policymakers (Cambridge, UK: Cambridge University Press,

2007) at p. 9.

3 Ibid p.11-18.

${ }^{4}$ Ibid. at p. 411.
} 
indeed not at the same time. Indeed the painful paradox about human-induced climate change is that societies that have contributed most to the problem, are unlikely to suffer the worst of the consequences. ${ }^{5}$ Consequently, the challenge that this poses at the international level is how to regulate in a way that is acceptable to all states given the differentiated and in some cases very delayed effects of climate change. ${ }^{6}$

\section{Regulatory transitions in favour of climate change mitigation and adaptation}

The collective regulation of climate change requires significant trade-offs between and by states. Although there are, at the international level, a significant number of policy and regulatory interventions designed to mitigate climate change, it is often not immediately apparent how the myriad policies are integrated and connected to aggregate targets. There is a particular need for clear and credible policies that will contribute to aggregate emissions caps set on the basis of the long term targets. However, because the implementation of climate change policies and regulations requires fundamental changes in the longestablished repertoires of nations and their citizens; it is critical that such interventions enjoy a significant level of legitimacy if they are to succeed. ${ }^{7}$ This paper contributes to the debate about governance for climate change, addressing in particular the role of culture and legitimacy in the transition towards effective international regulation.

In the context of climate change regulation, it is clear that given the spatial and temporal challenges outlined earlier, transitions to new effective regimes will likely be contested since the repertoires that currently define progress and development enjoy a high degree of acceptance. Transitions that are seen as curbing such a worldview will therefore struggle to gain acceptance. In addition to that, given the incidence of impacts of rising temperatures, it is almost unavoidable that those who will be asked to contribute more, will not be affected directly by the consequences of climate change, although the chain of causation will likely lead to them.

Studies from the technological industries give us a good overview of the difficulties in trying to establish transitions within particularly well-settled systems. ${ }^{8}$ For example, the car transport system, is partly stabilised by high mobility lifestyles and cultural meanings that associate cars with freedom, individuality,

\footnotetext{
5 SH Schneider, "Can we estimate the likelihood of climatic changes at 2100?" Climatic Change 52 (2002), pp.441-451. RSJ Tol, "Is the uncertainty about climate change too large for expected cost-benefit analysis?" Climatic Change 56 (2003), pp. 265-289. ${ }^{6}$ RSJ Tol, "Is the uncertainty about climate change too large for expected cost-benefit analysis?".

${ }^{7}$ Karin Bäckstrand, "Democratizing global governance of climate change after Copenhagen" Chapter contribution to the Oxford Handbook on Climate Change and Society, edited by John S. Dryzek, Richard B. Norgaard and David Schlosberg 2011 (on file with author).

${ }^{8}$ See for example S Schaefer "Legitimacy and the international regulation of geoengineering with solar radiation management: Prospects for normative institutional design theory" Paper prepared for the workshop "The Ethics of Geoengineering with Solar Radiation Management" at the University of Montana, October 18-20, 2010. Professor Frank Geels has undertaken leading work on transitions in socio-technical developments and his methodology informs the discussion that follows. See F Geels,

"Technological transitions as evolutionary reconfiguration processes: A multi-level perspective and a case-study", Research Policy, 31(8/9) (2002), pp.1257-1274; FW Geels, "From sectoral systems of innovation to socio-technical systems: Insights about dynamics and change from sociology and institutional theory", Research Policy, 33(6/7) (2004), pp. 897-920; FW Geels and R Kemp, "Dynamics in socio-technical systems: Typology of change processes and contrasting case studies", Technology in Society, 29(4)(2007), pp.441-455.
} 
adventure, and status. The literature on path dependence also recognises 'car culture' as one of the lock-in mechanisms for the transport system. Existing participants within this system are stabilised by 'webs of interdependent relationships with buyers, suppliers, and financial backers...and patterns of culture, norms and ideology'. ${ }^{9}$ Another example from technological transitions may be garnered from innovations in coal burning systems in the West. For a long time, smoke was accepted as unavoidable nuisance of burning coal in domestic stoves. However, anti-smoke campaigns in the late 19th century coupled with strong advocacy from doctors and urban reformers, motivated the articulation of new perceptions of smoke as silent killer, which in turn stimulated smoke regulations and innovations in coal burning equipment. ${ }^{10} \mathrm{It}$ is clear, therefore, that in attempting to replace systems that enjoy considerable lock-in, it is almost always necessary to deconstruct existing cultural meanings. ${ }^{11}$ This is true of technological systems. It is also true of regulatory systems.

Transitions thinking is also relevant with regard to radical breaks with the past, which usually suffer from the 'liability of newness'. ${ }^{12}$ This is because the new regimes are likely to be perceived as strange and unfamiliar with regard to established cognitive categories, or as inappropriate with regard to behavioural norms. ${ }^{13}$ Again, a good illustration may be sourced from technological studies. Du Gay outlines the case of the Walkman personal stereo, which when first introduced was considered 'out of place'. ${ }^{14}$ Not only was the design of the device unfamiliar but it also failed to fit existing conceptual categories, combining as it did two paradigms: the pursuit of private pleasure (listening to one's own music) within the public realm. The mixing of paradigms spawned some spirited discourse about the social effects of personal stereos: visionary voices welcomed individual choice and freedom, while status-quo advocates saw the personal stereo as destroyer of public life and community values. There were attempts to suppress personal stereos in public life, e.g. ban it from the London Underground. ${ }^{15}$ Over time, however, personal music systems have become an accepted, and some would argue an essential, part of life.

These examples and considerations suggest that 'culture' is relevant at different levels of adaptive transitions, something that is explicitly acknowledged in multi-level perspective on change. ${ }^{16}$ However, in

\footnotetext{
${ }^{9} \mathrm{~F}$. Geels, "Technological transitions as evolutionary reconfiguration processes: A multi-level perspective and a case-study". See also ML Tushman and E Romanelli "Organizational evolution: A metamorphosis model of convergence and reorientation" in L.L. Cummings \& B.M. Staw (eds.), Research in Organizational Behavior, Vol. 7, (Greenwich, CT: JAI Press, 1985), pp.171-222. 10P Thorsheim, Inventing Pollution: Coal, Smoke and Culture in Britain Since 1800 (Ohio University Press: Athens, 2006); S Schaefer "Legitimacy and the international regulation of geoengineering with solar radiation management: Prospects for normative institutional design theory".

11 lbid.

12 JH Freeman, GR Carroll, and MT Hannan, "The liability of newness: Age dependence in organizational death rates", American Sociological Review, 48(5)(1983), pp. 692-710

13 JA Schumpeter, The Theory of Economic Development: An Inquiry into Profits, Capital, Credit, Interest, and the Business Cycle (Cambridge, MA: Harvard University Press, 1934), p.86-87: In the breast of one who wishes to do something new, the forces of habit rise up and bear witness against the embryonic project...Any deviating conduct by a member of a social group is condemned...Even a mere astonishment at the deviation...exercises a pressure on the individual".

14 P Du Gay, S Hall, L Janes, H MacKay, and K Negus, Doing Cultural Studies: The Story of the Sony Walkman, (London : Sage

Publications, 1997).

15 Ibid.

${ }^{16} \mathrm{~F}$ Geels, "Technological transitions as evolutionary reconfiguration processes: A multi-level perspective and a case-study"; FW Geels and R Kemp, "Dynamics in socio-technical systems: Typology of change processes and contrasting case studies"
} 
the context of climate change regulation, despite the acknowledgement that culture is important, the literature on regulatory transitions within this domain have not systematically analysed the dynamics of culture and the mechanisms through which it exerts influence. The article aims to address this problem in two steps. Because 'culture' is a diffuse concept with multiple meanings, the first step is to articulate my position within the broader social science approaches that deal with culture and amplify the element of change. The second step is to conceptualise the relationship between this view of culture and regulatory transitions on climate change and thereby outline a discursive framework for systematically introducing legitimacy considerations within such transitions.

\section{Culture and the omnipresence of change}

Culture is the cumulative creation of human beings 'which transforms individuals into organised groups and gives these groups an almost indefinite continuity. ${ }^{17} \mathrm{An}$-Naim suggests that we use the term culture in what he calls 'its widest meaning' denoting 'the totality of values, institutions and forms of behaviour transmitted within a society, as well as the material goods produced by men [and women] ... This wide concept of culture covers Weltanschaung [worldview], ideologies and cognitive behaviour.'18 With this broad definition of culture, An-Naim does not mean to suggest that culture is everything but rather that there is a cultural dimension to every aspect of human activity'. ${ }^{19}$ Culture is therefore a source of the individual and communal worldview. It provides both the individual and the community with the values and interests to be pursued in life, as well as the legitimate means of pursuing them. It stipulates the norms and values that contribute to people's perception of their self-interest and the goals and methods of individual and collective struggles for power within a society and between societies. As such, culture is a primary force in the socialisation of the individual and a major determinant of the consciousness and experience of the community. As Geertz observes, without culture or enculturation: 20

[H]uman beings would be unworkable monstrosities with very few useful instincts, fewer recognisable sentiments, and no intellect; mental basket cases. As our central nervous system...grew up in great part in interaction with culture, it is incapable of directing our behaviour or organising our experience without the guidance provided by systems of significant symbols...Such symbols are thus not mere expressions, instrumentalities or correlates of our biological, psychological and social existence, they are prerequisites of it.

Amplifying this understanding of the role of culture as a system of symbols, Geertz defines culture as 'historically transmitted patterns of meaning, embodied in symbols, a system of inherited conceptions expressed in symbolic forms by means of which men communicate, perpetuate and develop their knowledge about and attitudes towards life.

Lindholm explains these observations further by pointing out that in any social group there are certain routines of practice which include skills, competencies, the exercise of rules or formulation of frameworks,

\footnotetext{
${ }^{17}$ B Malinowski 'Culture'(1931) 4 Encyclopaedia of Social Sciences p.621.

${ }^{18} \mathrm{AA}$ An-Naim "Towards a cross-cultural approach to defining to defining intenational standards of human rights: The meaning of cruel, inhuman or degrading treatment or punishment" in AA An-Naim (ed) Human Rights in Cross-Cultural Perspectives: A Quest for Consensus (Philadelphia: University of Pennsylvania Press, 1991) p.19 at p.23

${ }^{19}$ AA An-Naim "Problems of universal cultural legitimacy for human rights" in AA An-Naim \& FM Deng (eds) Human rights in Africa: Cross-cultural perspectives, (Washington D.C.: Brookings Institution, 1990) p.331 at pp. 335-336.

20 Ibid.
} 
opinions, aspirations, sensibilities, roles or institutions. ${ }^{21}$ These routines are taken for granted and shared as a matter of course. Newcomers to the group have no viable alternative but to acquire those routines of practice if they are to have access to the activities and experiences that define social practice. As historical social structures, traditions are shared and unquestioned routines which are reproduced by the individuals in a given generation, passed on to newcomers who are included in the group as they are born or become assimilated into the group. Thus, culture is learned and shared behaviour which helps systematise the way people go about their lives. ${ }^{22}$ Culture establishes a set pattern of belief and assumptions by means of which everyone can project their perceptions and expectations onto other people without thinking about it. This in turn provides consistency, predictability and stability by simplifying social interaction.

Whilst this view of culture is fundamentally correct, it is vital to avoid conceptualising culture 'as a static, homogenous, and bounded entity defined by its specific "traits"'. ${ }^{23}$ In this regard, Preis argues that cultures are not quantifiable things that sometimes happen to come into contact with each other. ${ }^{24}$ Instead, culture is at once a dynamic process and specific practice without discrete boundaries. She notes: ${ }^{25}$

Although the classic vision of unique cultural patterns has proven merit, its limitations are seen today as serious indeed. Most importantly, this vision emphasises shared patterns at the expense of processes of change and internal inconsistencies, conflicts and contradictions.

Lindholm concedes this point when he observes that social practices are reproduced and transformed only through the activities of individuals, and are suspended or discontinued when the upholders of a given tradition entertain viable alternatives to it. ${ }^{26}$ His main point in this regard is that traditions are reproduced only through intentional human agency and not as something that exists independently outside of the participants within a particular culture.

Nyamu-Musembi lends her weight behind the importance of human agency and against a deterministic conception of culture. Drawing upon the findings of her research on women's property rights in Kenya, she observes that 'the dynamism reflected in the variation and flexibility that abound in actual social practice point to the fact that culture is not deterministic'. ${ }^{27}$ In her view, human actors do possess the agency that enables them to act against established cultural expectations, and, therefore opening up the possibility of the departure from long accepted interpretations of culture.

The above analysis points out one crucial characteristic of culture that is more often than not omitted in definitions and discussions concerning the concept. This aspect of culture highlights not only its resilience and endurance but also its permeability and flexibility. In this regard, it is important to note that all cultures

\footnotetext{
${ }^{21}$ T Lindholm "Coming to term with tradition" in H Hoibraden \& I Gullvag (eds) Essays in Pragmatic Philosophy (Oslo: Norwegian University Press, 1985) p.103 at p.110.

22 G Fisher Mindsets: The Role of Culture and Perception in International Relations (Yarmouth, ME: Intercultural Press, 1988) at p.46.

${ }^{23}$ AS Preis 'Human rights as cultural practice: An anthropological critique' (1996) 18 Human Rights Quarterly 286 p.289.

24 Ibid.

25 Ibid.

${ }^{26}$ T Lindholm 'Coming to terms with tradition' in H. Hoibraden \& I Gullvag (eds) Essays in pragmatic philosophy (Oslo: Norwegian University Press, 1985) p 103. at p 108.

${ }^{27} \mathrm{C}$ Nyamu-Musembi 'Are local norms and practices fences or pathways? The example of women's property rights' in AA AnNaim \& J Hammond (eds) Cultural transformation and human rights in African societies (London and New York: Zed Books Ltd, 2002) p 127 at $p 134$.
} 
are 'eclectic, dynamic, and subject to significant alteration over time. ${ }^{28}$ They are susceptible to and do respond to influence by social, economic and political forces. Thus culture is neither a monolithic nor unchanging set of practices. In fact, according to An-Naim, one of the apparent paradoxes of culture is the way it combines stability with dynamic continuous change. ${ }^{29}$ As Herskovitz correctly observes, 'culture is flexible and holds many possibilities of choice within its framework...[T]o recognize the values held by a given people [at a particular period] in no way implies that these values are a constant factor in the lives of succeeding generations of the same group'. ${ }^{30}$

Thus culture and cultural practices are not immutable but rather are inherently responsive to new ideas and ways of doing things suggested by external influences or required by internal needs. Similarly, Hitchcock aptly captures the shifting yet very settled nature of culture when he posits that: ${ }^{31}$

Culture, shared meanings, practices, and symbols that constitute the human world, does not present itself neutrally or with one voice. It is always multi-vocal and over-determined, and both the observers and the observed are always enmeshed in it...There is no privileged position, no absolute perspective, no final recounting.'

Viewed from this perspective, it is clear that international discourse on the appropriate interventions to combat climate change is but a species of cultural interaction. Consequently, establishing international approaches to solving the problem as agreed by states will bring in the dynamics of change described above. It is clear that even though attempting to establish regulatory frameworks for addressing the problem of climate change will meet significant challenges, given the spatial and temporal challenges raised by climate change, there is significant scope for establishing innovative and ultimately effective solutions at the international level. Despite cultural factors that support regulatory frameworks amenable to climate change-inducing behaviour within different states, there are immense possibilities for sea-changes even amongst the community of states for tackling such. Policy makers addressing the issue must grasp the opportunities offered by the idea of change within cultural constructs and consider interventions which aim to displace the legitimacy of the existing narratives with new perspectives that enjoy greater cultural legitimacy.

\section{Cultural legitimacy and international regulation}

While it has been acknowledged that legitimacy is an essential aspect of any potential governance scheme directed at regulating climate change, ${ }^{32}$ conceptual clarity has so far been lacking in relation to the manner in which the concept can be introduced into transitions in climate change regulation. Consequently, in this section I focus on the concept of legitimacy and outline a discursive framework for achieving its systematic introduction towards efforts in international climate change regulation.

\footnotetext{
${ }^{28}$ B Ibhawoh 'Between culture and constitution: Evaluating the cultural legitimacy of human rights in the African state' (2000) 22 Human Rights Quarterly p 838 at p 841.

${ }^{29}$ AA An-Naim "Problems of universal cultural legitimacy for human rights".

30 MJ Herskovitz Cultural dynamics (New York: Knopf, 1964), pp.49-50. See also J Eekelaar 'Children between cultures' International Journal of Law, Policy and the Family 18(2004), p.178 at p.182 observing on the changing nature of 'black' identity. ${ }^{31}$ RK Hitchcock 'Anthropological research and remote area development among the Botswana baSarwa' in RK Hitchcock, QN Parsons \& J Taylor (eds) Research development in Botswana (Gaborone: Botswana Society, 1985) p.285 at p.286.

32 WN Adger, K Brown, J Fairbrass, A Jordan, J Paavola, S Rosendo and G Seyfang, "Governance for sustainability: towards a 'thick' analysis of environmental decisionmaking" Environment and Planning A 35(6) (2003, pp.1095 - 1110; F Berkes, "CrossScale Institutional Linkages: Perspectives from Bottom Up" in Ostrom, E., Dietz, T., N Dolzak, PC Stern, S Stonich., and Weber, E.U. (eds), The Drama of the Commons (Washington, DC: National Academy Press, 2001), pp. 293-321.
} 
Cultural legitimacy denotes the quality of being in conformity with the accepted principles or rules and standards of a particular culture. The defining characteristic of cultural legitimacy is the authority and reverence derived from internal validity. ${ }^{33}$ A culturally legitimate norm, rule or value is respected and observed by members of the particular community, presumably because it is assumed to bring benefits (whether real or imagined, tangible or intangible) to the members of that particular community. The corollary of this is that a rule or norm which does not command adequate legitimacy will not enjoy sufficient observance or support. Such a rule is more likely to be breached than observed. Thus, at the most basic level, a social or political order can be described as legitimate when its subjects consider its rules to be appropriate and binding. That is they accept the authoritative allocation of values occurring within it, which may be costly for them, even in the absence of sanctioning mechanisms.

In the context of international climate change regulation, the key question is how legitimacy-enhancing attributes can be imbued within regulatory interventions right from the outset so that their impact is immediate. In order to do this, it is essential to consider different elements of legitimacy in so far as they pertain to international regulation. Consequently, in the remainder of this section, I introduce three dimensions of the concept in reference to which comprehensive frameworks of legitimate regulation may be developed. These three dimensions include input, throughput, and output legitimacy. ${ }^{34}$

Input legitimacy refers to the notion that those being ruled should have something to say in the policymaking process. In a representative democracy, input is secured through the right to vote and assures the accountability of decision-makers to those whom they represent. Different societal interests are thus represented by those who were elected to do so. In a direct democracy, input is not mediated through representation but instead occurs through the direct participation of those governed. In settings beyond the nation-state it is very difficult to secure input legitimacy. Technically, decision-makers at the international level are accountable to those who elected them as their representatives in the context of national elections. However, the national discourse in the run-up to national elections tends to focus on national issues. There is thus a lack of information on the international issues policymakers will have to deal with when in office. Additionally, two other problems arise in the context of input-legitimacy at the international level. Firstly, the absence of strong transnational interest representation leads to decision-making that is not informed by the interests of those affected. Secondly, and most significantly in regard to global issues such as consciously altering the climate, those affected by a decision are often not represented in the decision-making process. The latter can be referred to as lack of input-congruency 35 since the group of people who are represented in the decision-making process is not congruent with the group of people who are affected by political outcomes.

Throughput legitimacy refers to the quality of the process by which rules are determined. To ensure throughput legitimacy, it is important that it is clear who is responsible for which decisions. Transparency is thus a central feature of a legitimate decision-making process. From a democratic theory perspective, a legitimate decision-making process also cannot simply rely on majority voting, but must involve deliberative

\footnotetext{
${ }^{33}$ AA An-Naim "Problems of universal cultural legitimacy for human rights" p.336.

${ }^{34}$ Schaefer has constructed a useful typology for considering legitimacy in the regulatory context. The typology follows a processual model whereby legitimacy is considered at 3 distinct stages of regulatory interventions. See S Schaefer "Legitimacy and the international regulation of geoengineering with solar radiation management: Prospects for normative institutional design theory"

35 Ibid.
} 
processes in which individual interests are subjected to public scrutiny. ${ }^{36}$ Thus, in order to secure throughput legitimacy, it is essential that at the international level decisions are not simply made through diplomatic bargaining, but via a process of deliberative argumentation in which individual interests are scrutinised and debated in regard to their justifiability.

Output legitimacy refers to the substantial quality of rules themselves. This is an important aspect of the concept of legitimacy since even a system which follows a legitimate process in its decision-making but produces unacceptable outcomes must be considered illegitimate. Its subjects will not voluntarily comply with its rules. Similarly as with input legitimacy, a deficiency in output legitimacy occurs when there is no congruency between the reach of a rule and the extent of the relevant social context to which it applies. ${ }^{37}$ The denationalisation of social contexts, i.e. the increase in externalities that operate across borders (transboundary effects), has led to a lack of output-congruency in the nation-state; this reminds us that international institutions are an (albeit imperfect) response to a deficit in legitimacy, and not its origin. In terms of output-congruency with regard to transnational issues, international institutions are an improvement to the territorially-bound reach of decisions made in nation-states. Nonetheless, it must be noted that most international institutions from the viewpoint of output-congruency are still insufficient, while at the same time overstepping the boundaries of legitimate decision-making with regard to input congruency. Shortly put, international institutions do not do enough in terms of output, but what they do is already too much to be justified in terms of input.

It is clear, therefore, that legitimacy is key to the proper functioning of interstate regulatory arrangements. 38 However, ensuring that legitimacy is introduced at all stages of the regulatory process is a considerable challenge. Given the regionally differentiated effects of climate change, there is likely to be significant disagreement between states on the desirability of the regulatory choices made to tackle the problem. Deliberate strategies that allow legitimacy-enhancing features to be designed into climate change regulatory frameworks at the input stage and throughput stages are one way of ensuring efficacy and acceptance of regulatory interventions. Additionally, systems that have measurable attributes to assess the outputs are also likely to be more resilient. In order to avoid tensions and conflict and to ensure good governance between different states, legitimate regulatory schemes at all governance levels are needed.

\section{Cultural legitimacy and regulatory transitions in favour of climate change mitigation}

Within international climate change regulation, actors try to confer legitimacy to their actions and innovations by linking their discourses to broad but diffuse ideographs. ${ }^{39}$ These cultural actions are situated both internationally as well as at the local level. Institutional theory suggests that the legitimacy of existing regimes depends on conformity to broader cognitive institutions (ideologies, generalised belief systems, societal discourses), normative institutions (values, role expectations, standards of acceptability) and

\footnotetext{
36 Ibid.

${ }^{37}$ Ibid.

$38 \mathrm{~V}$ Schmidt "'Taking ideas and discourse seriously: Explaining change through discoursive institutionalism as the fourth 'new institutionalism"', European Political Science Review 2 (2010), pp. 1-25.

${ }^{39}$ An ideograph is: "an ordinary language term..., a high order abstraction, representing collective commitment to a particular but equivocal and ill-defined normative goal. It... guides behaviour and belief into channels easily recognized by a community as acceptable and laudable" (McGee, 1980: 15).
} 
regulatory institutions (laws, regulations)..$^{40}$ From a substantive viewpoint, this legitimacy is continuously reproduced and defended against challenges.

Regime actors engage in debates and contestation to articulate, reproduce, and adjust the discourses that provide meaning and legitimacy for particular regulatory issues. Radical novelties initially have low legitimacy, because they suffer from the 'liability of newness' and are being perceived as strange, weird, or inappropriate. ${ }^{41}$ Consequently, in the early phase of transitions, the enhancement of cultural legitimacy is therefore a crucial process. Again, technological studies offer great examples relating to the uneven and uncertain nature of transitions: radical innovations are initially characterised by pervasive uncertainty, e.g. about, user requirements, technical performance, price and resilience. It is therefore difficult to make reliable cost-benefit calculations that underpin rational decision-making. Early investments, ventures, are therefore, at least partly, an act of faith that involves beliefs and feelings. Similarly, new regulatory systems need resources from their environment, and, in the end, the motivating factor for external actors to give such resources is their belief or feeling that the framework is indeed competent, efficient, effective, worthy, appropriate, and/or needed. Perceived legitimacy provides a basis for decision-making that is different from means-ends rationality. ${ }^{42}$ Cultural legitimacy thus has positive effects on attracting attention, resources and support from relevant external actors. ${ }^{43}$ Investments, support and acceptance, in turn, help regulatory transitions gather momentum in the early phases of transitions.

Because the literature already recognises the effects of cultural legitimacy, in this, the remainder, of the paper, I specifically focus on the origins and creation of legitimacy, particularly with regard to transitions in climate change regulation and attempt to link these perspectives with the processual and qualitative ideas of input, throughtput and output legitimacy.

The cultural legitimacy of efficacious climate change regulatory frameworks is the outcome of discursive struggles between those who oppose drastic changes to emissions pathways (for whatever their strategic reasons) and those champion major redrawing of emissions and consumptive patterns to address climate change. The proponents articulate promises, expectations, and visions that highlight the advantages of particular innovations, how they will solve particular climate change problems and avert the externalities of rising global temperatures (e.g. creation of new opportunities; development of newer, cleaner technologieswhich can only be a good thing, it is argued. The opponents tend to highlight disadvantages, risks, and possible negative side-effects (e.g. limitations in productivity; reduction in competitiveness, etc). From a practical viewpoint, both discourses struggle with each other; actors develop arguments and counterarguments in response to each other and changing public perceptions. Climate change struggles are thus played out as 'regulatory dramas' on the public stage with actors aiming to influence the perceptions and appreciations of relevant 'audiences' (who provide resources, support, acceptance etc.).44

Thus, insights into institutional dynamics of decision making also show that all environmental decisions implicitly or explicitly involve questions, as well as trade-offs, regarding economic efficiency, environmental

\footnotetext{
40 FW Geels \& B Verhees "Cultural legitimacy and framing struggles in innovation journeys: A cultural-performative perspective and a case study of Dutch nuclear energy (1945-1986)" Technological Forecasting \& Social Change 78 (6)(2011), pp. 910-930.

41 Ibid.

42 Ibid.

$43 \mathrm{lbid}$.

44 Ibid.
} 
effectiveness, equity and political legitimacy. ${ }^{45}$ All environmental decisions produce distinct sets of institutional forms with different outcomes, different degrees of uncertainty, and different trade-offs for each particular alternative and derived outcome. Hence, international environmental decision making is likely to involve a plurality of stakeholders with divergent views over these implementation alternatives and outcomes. Stakeholders' competing views are likely to be a product of their diverse socio-cultural contexts and their interests. This highlights the importance of being sensitive to this pluralism in the design and implementation of environmental decisions. Designing input, throughput and output legitimacy into any international regulatory responses is therefore one way of ensuring the efficacy of international interventions. Discourses that score higher on more of these aspects of legitimacy, have more strength, produce more legitimacy, and thus generate more effects on external actors who provide resources, support and protection. They have more foundation in terms of their legitimacy and are more likely to result in lasting transitions. By deliberately adopting strategies that increase the incidence of legitimacy enhancing features within input, throughput and output legitimacy, it is likely that the regulatory transitions to a more credible climate change regime will emerge.

45 Mary Gearey and Paul Jeffrey "Concepts of legitimacy within the context of adaptive water management strategies" Ecological Economics, 60 (2006), pp. 129-137. 